\title{
LESSONS FROM THE STOCKHOLM CONGESTION CHARGING TRIAL
}

\author{
Jonas Eliasson \\ Centre for Transport Studies, Royal Institute of Technology \\ WSP Analysis \& Strategy (formerly Transek)
}

\section{Introduction}

Among transport economists and traffic planners, congestion pricing has been advocated for a long time as an efficient means to reduce road congestion. Up until recent years, the idea had been applied almost nowhere, with Singapore the sole exception. In the last few years, however, congestion pricing has been introduced in various forms, with London and Stockholm being the most ambitious systems in the sense that the congestion charges apply to the entire urban core.

The Stockholm case is interesting for many reasons. Obviously, the opportunity to gauge the effects of congestion charges on traffic, congestion levels and travel behaviour has attracted great interest. But perhaps even more interesting is the fact that the congestion charges survived a very complicated political and legal processes, and a dedicated referendum that had initially been forced through by the opponents of the charges. In many ways, the most interesting from the perspective of other cities is the story of how and why the Stockholm charges went from "the most expensive way ever devised to commit political suicide ${ }^{1 "}$ to something termed by initially hostile media as a "success story" with wide public and political support. The purpose of this article is to discuss what can be learnt from the Stockholm experiences - what was expected and unexpected, what made the charges be viewed as a "success" and what lessons can be learnt for other cities. In order to do this, I will have to (rather briefly) describe the background and the planning process of the charging trial - not by any means the complete story of the process, but just enough detail to explain my conclusions.

Obviously, this account is at least partly a subjective story. I was, together with varying colleagues, responsible for the initial proposed design and the forecasts of the traffic effects. Later, I was the chairman and spokesperson for the scientific expert panel that scrutinised and summarised the extensive evaluation of the effects of the charges, and was also responsible for the cost-benefit analysis. Clearly, my story will be coloured by my own perspective and my own experiences and impressions. Nevertheless, I hope that the conclusions I draw form my experiences and observations during and after the trial may be of some interest and use, subjective and contestable as they may be.

\footnotetext{
${ }^{1}$ Quote Gunnar Söderholm, social-democratic head of the Congestion Charging Office during the trial, when (after the trial) describing the local Social Democrats' feelings when the national Social Democratic government more or less forced the congestion charges onto the local Stockholm party district.

${ }^{2}$ For example Dagens Nyheter, Sweden's biggest morning paper, 22 June 2006.
} 


\section{Background - road pricing in Stockholm}

The theoretical case for road pricing has been established for a long time. The earliest pieces of the theory came with Dupuit (1849), Pigou (1918) and Knight (1924), and already in the early 1960's, the famous "Smeed report" (HMSO, 1964) could state that "the theoretical case for road pricing is irrefutable". But nowhere was road pricing introduced - not until 1975, when Singapore became the first city to introduce urban road pricing as a means to reduce congestion. Several other cities made attempts to conduct serious trials, but for various reasons all of them came to nothing (an early overview can be found in May, 1992).

Around 1990, Norway pioneered urban cordon tolls, which was a novelty compared to the ubiquitous toll roads. This had nothing to do with congestion charging, but attracted interest by showing that it was technically possible to establish automatic payment systems in urban areas. Further, it showed that it was possible to achieve quite high levels of public approval of road charges if the payments were linked to something that was clearly perceived as being "useful" - in Norway's case, new roadbuilding programmes. At the time in Norway, though, it was considered unacceptable to design the charges to simultaneously reduce congestion. On the contrary, the Norwegian systems were configured specifically not to affect traffic levels.

Sweden belongs to the fairly small group of countries that has no tradition whatsoever of toll roads. But the experiences in Norway was of course followed closely in Sweden. The idea of charging road users had also been suggested several times in different contexts, either as a source of revenues, or motivated by fairness reasons ("users should pay") or efficiency reasons ("external costs should be priced"). The logic of the Norwegian toll roads was in the background when the so called Dennis agreement (named after the negotiator) was struck in Stockholm at the beginning of the 1990s (a description and analysis can be found in Ahlstrand, 1998). The Dennis agreement included a charging cordon around the inner city, mainly as a means of paying for investments in roads and public transport. But in spite of being primarily designed with financial aims in mind, the cordon charge was to a large extent publicly promoted using arguments about reducing congestion and improving the environment in the inner city. However, the charges were not especially well devised from the point of view of traffic regulation - not as bad as they were later painted, but not particularly good. Among other things, the system of tolls was criticised because the toll booths were located outside the planned ring roads around the city centre - once the toll had been paid, there was nothing to prevent vehicles travelling through the city centre instead of taking the ring roads around the city. Hence, congestion charging advocates claimed that the Dennis-tolls would have no congestion-reducing effect at all.

Interestingly enough, later analyses showed that this claim was wrong. The Dennistolls would in fact have reduced the level of traffic in and around the city centre, and thereby the congestion on approach roads and in the inner city. But the analyses showing that the Dennis-tolls were not nearly as flawed as had first been thought did not come until later. By then, the media battle had been more or less lost. Everybody seemed to dislike the Dennis-tolls, some because they disapproved of road charging of any kind, others because they were the wrong sort of charges, and others still because they were designed to finance projects they disapproved of. The Dennis agreement collapsed in 1997, for a number of different reasons - the fact that virtually 
nobody liked (or at least championed) the tolls that were essential for the funding was a large part of the explanation.

This illustrates two lessons from the road pricing acceptability literature ${ }^{3}$. First, the design of the charge must be in accordance with the arguments used to justify them. The Dennis-tolls were designed to provide revenues - traffic reduction in the inner city was just a nice side effect. When attempts were made to "sell" the charges using the secondary argument - improvements in the environment and in the level of traffic flow - the advocates of the package got in an untenable debate position: the arguments used for the charges couldn't explain why they were designed the way they were.

The second lesson is how important it is to have demonstrably solid grounds for the decisions taken, supported by credible figures. The debate over the Dennis-tolls could have taken a rather different course if the forecasts of traffic reductions had been available from the beginning. In fact, by the time those predictions were published, decisions had already been made and debating positions already established, and so it was too late.

It was obvious that the Dennis-tolls were not constructed in an optimal way - but what should have been done instead? The question of road pricing was off the agenda for the time being, but many - perhaps even most - traffic planners were convinced that this was only temporary. As a result, research and development work on congestion charging continued, albeit out of the media spotlight. This continued applied and theoretical research would prove to be crucial, because next time the question hit the political agenda, researchers and practitioners would be prepared.

\subsection{Prologue to the 2002 election}

Once the dust had settled after the collapse of the Dennis agreement, a new attempt was launched to reach agreement on Stockholm's traffic problems, in the form of the Stockholm Commission, set up in the year 2000. The Stockholm Commission was a parliamentary committee with several tasks. The most difficult one would be prioritising between various possible investment plans, and preferably also an attempt to produce a realistic funding strategy. Eventually the commission produced an order of priority from the list of possible investments. The whole list of measures and investments would cost almost 100 billion SEK - more than half the government's investment budget for rather more than the next ten years. Funding was once again the stumbling block. Hardly surprisingly, the idea of road tolls cropped up again. Not only would they contribute to the funding of the project, but the possibility of using them as an environmental and traffic-regulating measure had been steadily gaining support. The Stockholm Commission was given broad terms of reference by the social-democratic government and asked to come up with proposals for road pricing. This was shortly before the 2002 general election campaign started in earnest, and the Moderates (the Swedish Conservative Party) saw an opportunity in the terms of reference given to the Stockholm Commission: they could claim that the Social Democrats were going to impose road charging in Stockholm. A vigorous advertising

\footnotetext{
${ }^{3}$ Jones $(1991,1995)$ give good overviews of the research field dealing with opinion-forming in connection with transport systems in general and congestion charging in particular. Eliasson and Lundberg (2002) is a somewhat newer overview of research results from a Swedish perspective, and is a little more focused on congestion charging.
} 
campaign was launched suggesting that this was the hidden agenda of the Social Democrats.

In fact the Social Democrats - unlike the Liberals (Folkpartiet), for instance - had never been especially interested in road charging. While the Dennis negotiations were taking place, the party had been divided on that point, and there was no party line now either. The Liberal Party in Stockholm had gradually changed its mind and, having been in favour, was now against (although it was not clear what their policy was at national level), and there was suddenly an opportunity to make road pricing a matter distinguishing political blocs: the Social Democrats could be painted into a corner alongside the Greens (Miljöpartiet) and the Left Socialists (Vänsterpartiet) as "the gang that secretly intends to impose road charging".

This led to Annika Billström's widely discussed election pledge made in a television programme: no road charging would be introduced during the next parliament. This pledge was not Billström's own idea, incidentally: it was the regional party organisation who had made the decision.

It is not clear what tactical considerations by the various parties lay behind the Conservatives' "anti-road-charging campaign" and later on the Social Democrats' manifesto pledge of "no road charges". One might speculate that the Social Democrats wanted to deflate the matter until the 2002 election was out of the way, so that they could then use the Stockholm Commission to put together a package of investments, funded in part by road charging, that they could offer to the electorate in the 2006 election for putting into practice during the subsequent parliament. That might have been a way of persuading voters to swallow the bitter pill of congestion charging with the aid of commitments to invest in measures they would not otherwise be able to afford. The non-socialist parties might have had a similar plan. Nobody who knew anything about the subject could seriously believe that the state would be able to fund the whole of the Stockholm Commission's wish-list - other sources of funding would have to be found, and the region would be forced to bear a proportion of the cost itself.

\section{After the 2002 election - a "full-scale trial"!}

However, something unexpected happened after the general election. In return for supporting a social-democratic government, the Green party got the social-democratic government to conduct that there would be a "full-scale, several-year trial with congestion charges in Stockholm". The Social Democrats on the national level then more or less forced Annika Billström, the Stockholm party leader, to accept this, in order not to jeopardise a social-democratic government. During the winter of 20022003, negotiations took place in the Greater Stockholm Council regarding when and how.

A full-scale trial - not just one single road or a few hundred cars - was that really necessary? It was hardly justified from a strictly scientific point of view. But perhaps with hindsight one can say that it was in fact the right thing to do from a political point of view, assuming it was considered from the start that congestion charging was a good idea. When we worried about the trial being too big. too expensive and too hurried, we didn't appreciate that only a full-scale system would be able to 
demonstrate clearly the advantages of congestion charging - reduced journey times. That was due in turn to the fact that we - and, I think, practically all other traffic experts - didn't expect the reduction in traffic levels would be visible to the naked eye. We had underestimated the visibility of the effects of the charge.

This may convey an impression of a clever, carefully designed plan to convince the public of the benefits of congestion charging. In fact, it was anything but. As soon became apparent, the advocates of the charges had underestimated the legal, technical, design and organisational difficulties. The original time plan was to start the system during the autumn of 2004 and run it at least until the next election, in the autumn of 2006. This time plan presupposed that a congestion charging system could be bought more or less off-the-shelf. It soon became clear that it was nowhere as easy. Just the necessary time for the procurement process would mean that the system could not start earlier than mid-2005. On top of that, the legal status was unclear: according to Swedish law, only the government could tax existing roads; hence, it was the government that would have to take the formal decision about the charges. But while the City of Stockholm quickly started planning, designing and procuring the charging system, essentially nothing happened at the government level.

The problems seemed so serious that even many congestion charging supporters thought that this was not a good idea. Many feared that this could never work - the time plan looked impossible, the political support too weak, the public opposition vehement and the legal status vague at best - and that this might even make the whole idea of congestion charging impossible for a long time.

\section{Designing the system}

\subsection{Transponders, the charging zone and the 20-kronor toll}

Half a year after the election, in March 2003, me and my colleagues at the small research-oriented consultancy Transek (later WSP Analysis \& Strategy) were contacted by the politicians to help them sort out all sorts of questions - designing the charges, choosing technology, planning the evaluation, coming up with a time plan, analysing effects for public transit etc. Fairly quickly, we decided to recommend a technology that was functionally similar to the Norwegian systems, minus the possibility to pay in cash - there was no space to build toll booths. ${ }^{4}$ Transponders inside the vehicles would be linked directly to bank accounts, so that the charge could be collected automatically when the vehicle passed through the charging cordon. Transponder identification would be supplemented by cameras recording the registration numbers of vehicles without transponders. We thought that if a vehicle did not have a transponder, the driver would have the opportunity to pay the charge using some customer service organisation, or over the counter in a shop, or by text messaging, more or less as in London. The big difference compared with London was (and is) that the Swedish system is based on the registration of passing vehicles (using transponders or video), whereas the London system merely checks (by video) that vehicles passing through the charging zone have paid. In London it is the responsibility of the driver to pay the correct sum in advance (or on the same day at the latest) - London does not have anything corresponding to the Swedish system's "tax demand" telling you on the spot what you have to pay. The key argument in

\footnotetext{
${ }^{4}$ The technical solution and the technical standard were slightly different, but the principle was the same.
} 
favour of (transponder-)registration rather than simply (video-)checking - as in London - was that it made it easier to apply different charges according to the time of day. Another consideration in favour of the Stockholm system was the anticipated lower operating costs in the long term. From a political point of view, it was important that the system should not simply be an experiment or a technical cul-desac: it really did have to be a full-scale trial system that could be made permanent if the results justified it.

We also proposed a toll system consisting of a cordon around the inner city with charges varying according to the time of day -20 kronor during the morning and evening peak hours, 10 kronor at other times, with the charging levels to be "phased in" over time. The charge levels were loosely based on earlier analyses, but there was no time for forecasts of the effects before the first report had to presented. As we were not well versed in the machinations of the media versus the politicians, we were not aware of how decisive the proposal of a specific charge level would be. Once a specific amount had been mentioned, it turned out to be difficult to change it - even if we had stated that it was only a first, approximate suggestion. It seems to be a general problem seems to be that if politicians discuss various different proposals, or change their minds in the light of new evidence (in this case traffic forecasts), they tend to be labelled as "indecisive" or "confused" in the media.

During the autumn a large number of traffic forecasts were made in order to prepare the way for a sensible system design. It was unclear what the quantitative goals for the system should be - in which dimensions different design proposals should be evaluated. Early on, politicians had suggested that the goal should be 10-15\% less traffic across the boundary of the inner city (or alternatively "at the most congested places and times", which is not quite the same thing). This was loosely based on earlier analyses carried out in different contexts, but we didn't think it was enough to hold on to when evaluating possible system designs on a detailed level. Moreover, part of our job was to check whether this was a reasonable goal - i.e., if this struck a reasonable balance between congestion reduction and not wanting unnecessarily high charging levels. So how should we evaluate suggested designs? An obvious candidate was trying to maximise social surplus (within reasonable bounds for charge levels and system complexity). However, there was a serious problem with this: we didn't really trust the travel times of the static network equilibrium model that was the only traffic model we had. In particular, we knew that the lack of "spillback congestion" made travel times underestimated. Instead, we settled for rules of thumb concentrating on the load factor of the bottle necks. The logic was that if we could lower the load factor of the bottlenecks, then queues caused by the bottlenecks would be reduced. We decided that the target should be a maximal relative speed reduction of $40 \%$ in the bottlenecks near the inner city, and a maximal relative speed reduction of $50 \%$ in the bottlenecks further out (all the while referring to model-calculated speeds). We thought that this would provide a "reasonable" congestion level - large enough to be appreciable, while the charge didn't have to be too high.

Fortunately, the forecasts showed that the "guesstimates" we had made during spring, turned out to have hit the target reasonably well. According to the traffic forecasts made in the autumn of 2003, the reduction in traffic levels in and around the inner city would be more or less what we considered to be "satisfactory". 
We tested several variants of the charging scheme. Eventually, it was decided that the system should look rather similar to the initial proposal - a simple cordon around the inner city. Compared to the initial proposal, there were minor changes such as adjusting the time periods and the maximum charge per day, and creating the "Lidingö exception" (explained below). That so few changes had to be made were mainly just luck - one of the lessons from trying out different designs in the forecasting models was that it was easy to design a charging system that created more problems than it solved, by "moving around" congestion. Hence, spending a lot of effort on the design of the charging system is imperative for any city wanting to introduce congestion charges - it's not just drawing a few lines on a map and converting 20 SEK to the local currency (which the planners of at least one (unnamed) city visiting Stockholm after the trial was about to do until we convinced them otherwise).

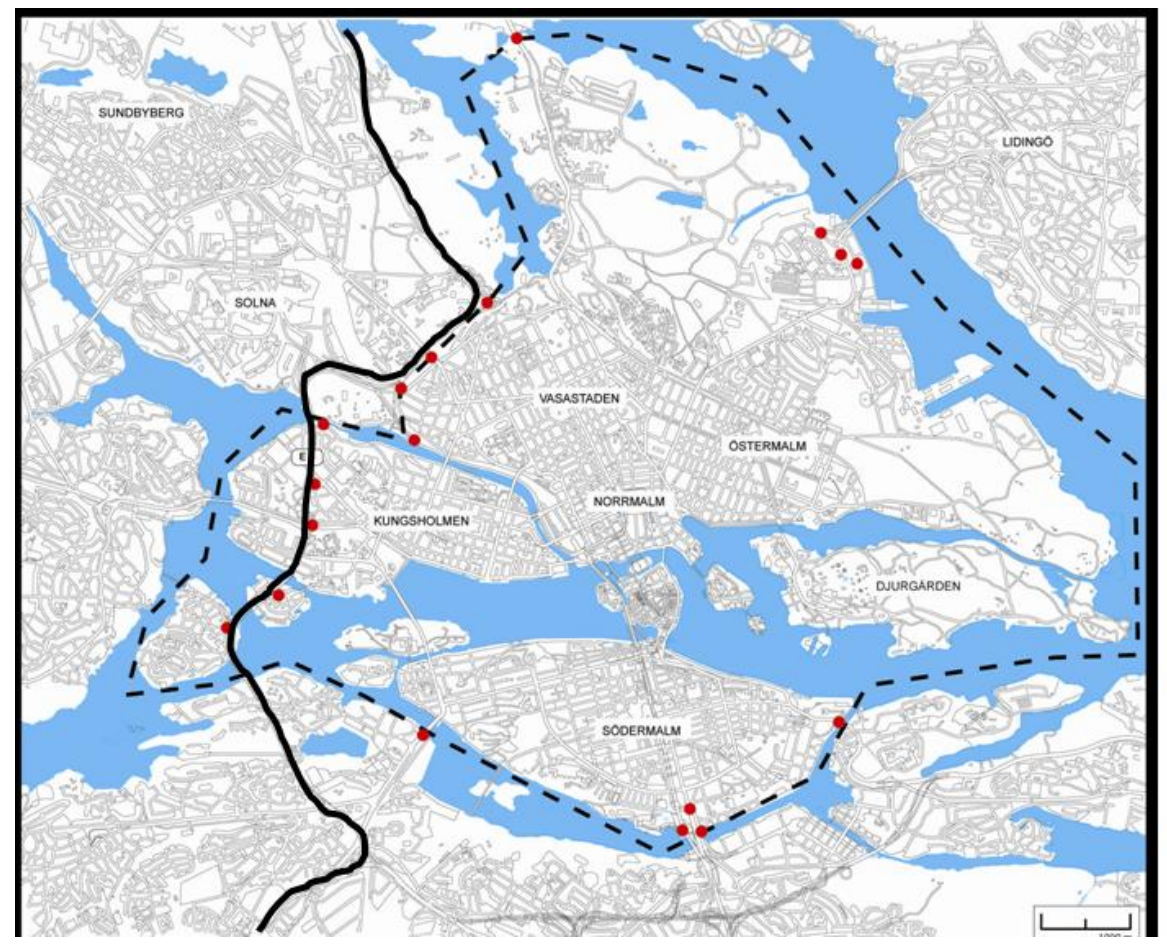

Figure 1. The charged area. The dashed line is the charging cordon, the dots are charging points and the solid line is the non-charged Essinge bypass.

Charges were to be levied weekdays between 6.30-18.30 according to the table below, with equal charges in both directions. Evenings, nights, Saturdays and Sundays, public holidays and days before public holidays were free of charge. Various exemptions (for e.g. taxis, buses, alternative-fuel cars and for by-pass traffic from and to the island of Lidingö) made nearly 30 percent of all car passages free of charge. The total daily payment of a vehicle was limited to SEK 60. 


\begin{tabular}{|l|r|}
\hline $6: 30-7: 00$ & 10 SEK \\
\hline $7: 00-7: 30$ & 15 SEK \\
\hline $7: 30-8: 30$ & 20 SEK \\
\hline $8: 30-9: 00$ & 15 SEK \\
\hline 9:00-15:30 & 10 SEK \\
\hline $15: 30-16: 00$ & 15 SEK \\
\hline $16: 00-17: 30$ & 20 SEK \\
\hline $17: 30-18: 00$ & 15 SEK \\
\hline $18: 00-18: 30$ & 10 SEK \\
\hline
\end{tabular}

Table 1. Charges in different time intervals (weekdays only).

There is a conflict between making congestion charging "efficient" in the theoretical sense, and making it easily understood. The system we designed was, I believe, relatively easily understood: one single charging cordon round the inner city, with the same charge at all points of entry, the same in both directions, and the same for both the morning and afternoon/evening peak periods. Certainly, the system could have been made more efficient if these symmetries had been abandoned. In particular, we discussed and tested different charges in opposite directions across the cordon: it could be motivated to have a lower charge for leaving the city in the morning than the charge for entering, and vice versa in the afternoon. Eventually, it was considered to be too complicated to explain for the (relatively small) gain in efficiency. In addition, there was a worry amongst politicians that it would make the system appear to be favouring inner city residents.

The most controversial design issue was whether there should be charging boundaries inside the inner city - sort of a wheel with spokes in it. Several politicians were very keen on this. Several variants of this were tried, but the traffic forecasts showed that this would create serious congestion problems on the Essinge bypass - the only real highway connecting northern and southern Stockholm. A design restriction was that the Essinge bypass had to be free of charge - that was a demand made by the Social Democrats in order to keep surrounding municipalities a little bit happier. The more we studied different forecasts, the more convinced we became that the combination of charging boundaries inside the inner city and a non-charged Essinge bypass would be fatal. It seemed more than likely to create more congestion than it relieved. But this was difficult for politicians to swallow. Several of them were afraid that if there were no charges inside the inner city, there would be a debate about them creating "a sanctuary for rich inner city dwellers" (inner city residents are typically more affluent than average). This fear was clearly not justified by the facts - calculations showed that, on average, people living in the inner city would pay considerably more in congestion charges than residents in any other geographical areas, even without extra inner city boundaries. But even so, it could be a political problem.

Eventually, the idea of inner city boundaries were abolished. But it turned out that the politicians had been right in their fears: a criticism constantly made of the charging system was that it favoured inner city dwellers. Publicised facts showing that inner city residents on average paid substantially more in tolls than any other geographical area, and on top of that got lower time gains than any other area, didn't help much. Opponents to charges still often held that it was "unfair that people living in the suburbs had to pay while those living in the city centre could drive for free". 


\subsection{The Lidingö exception}

Another design problem was caused by the case of Lidingö, an island with only one road connection to the rest of Sweden - which incidentally goes through the inner city of Stockholm. With a charging cordon around the inner city, Lidingö residents who commuted by car to anywhere but Lidingö and the inner city would have to pay the charge twice for a single journey. The possibilities of using public transport for journeys between Lidingö and other suburbs are very limited, so for most people it would mean greatly increased journey times to avoid the double charges. During the autumn, the idea was floated of creating a "Lidingö exception". At first we wrote the plan off as being far too complicated technically; but after some discussions with the experts, it turned out to be a possibility, albeit a complicated one.

It was only later that it became clear just how expensive this exception was. Not primarily because it is complicated to program a system that makes exceptions of certain vehicles: what really raises the cost is that it becomes necessary to identify literally all vehicles, because if one doesn't, a Lidingö exception might be missed. Without a Lidingö exception, it doesn't much matter if the detectors miss, say, one or two per cent of the vehicles. Few people are upset by not having to pay the congestion charge because a detector randomly happens to miss them. But with the Lidingö exception in operation, every missed vehicle might be a potentially furious Lidingö resident who has wrongly been made to pay the charge. Even a small number of such cases per day can become a major problem. And it is much more expensive to identify, say, $99.5 \%$ of vehicles than to identify $95 \%$ or $97 \%$, for instance. In order to gain the extra few per cent in efficiency, the images need to be checked manually in some way or other, and that soon becomes expensive. Had we realised just how expensive the Lidingö exception would be, it is unlikely that it would have been adopted - there were other options, after all. But hindsight is easy. The Lidingö exception still exists at the time of writing, but eventually it will hopefully (or even probably) be abolished due to the operating costs.

\section{Would the trial take place?}

By February 2004 the design of the system was complete. The original timetable, envisaging the commencement of charging in the autumn of 2004, was unrealistic from the start as there would be no time to clear the legal obstacles and complete procurement. But now a serious political battle broke out over the timetable, which seemed to be due to suspicions on the part of the Greens in particular that the Social Democrats were deliberately delaying the process. What made the suspicions worse seemed to be the extremely slow way in which the government managed their legal and administrative process. When it was finally decided in the summer of 2004 that equipment supplies would be the responsibility of an IBM-led consortium, the process was delayed even more by an official objection from the losing party. As late as the spring of 2005 , nobody knew if the trial would be able to take place at all. The starting date was first fixed as August 2005, but the legal proceedings took so long that it had to be postponed. In the spring of 2005 the last of the objections were overruled, and the implementation process began. The new starting date was designated January 3 2006. During the autumn newspaper headlines appeared in bolder and bolder print and Sweden braced itself for what was expected to be a congestion charging catastrophe. 
But at the original start date, in August 2005, the other part of the Stockholm trial started: the extended public transit services. This extension accounted for a little less than half of the total cost for the trial (around $1400 \mathrm{mSEK}$ compared to around 2000 mSEK for the congestion charging system), but turned out to yield nowhere near the effects of the charges in terms of congestion relief or social surplus. The extended services was motivated partly to meet increased demand for public transport, and partly by a political will to show "carrots" and not just "sticks". Most of the cost for this effort went to buying almost 200 new buses and operating 16 new bus lines, providing an efficient alternative for travelling at peak hours from the municipalities surrounding Stockholm into the inner city. A smaller part of the cost went to reinforce existing bus-, underground- and commuter train lines with additional departures wherever possible - due to limited track capacity, this was difficult to do. New parkand-ride facilities were built in the region, increasing the park-and-ride capacity with around $25 \%$. When the charges were postponed, it was too late to postpone the extended public transport, so it started in August 2005 as planned. From a pure evaluation perspective, this was of course lucky, since it made it easier to separate the effect of the new buses from the effect of the charges.

It turned, though, that very few car drivers were enticed to switch to public transport by the service extension. Moreover, the increase on passenger capacity by the buses was negligible on the aggregate level: at its peak, around 14000 trips were made each day by the buses, compared to well over one million public transport trips across the cordon each day. Another question is if the congestion tax would, in fact, have reduced vehicle traffic by so much if public transport had not been expanded. It is conceivable that the expansion boosted the effect of the congestion tax by making the switch from car to public transport easier. But even if this effect certainly exists, it must be small. The onboard surveys on the new buses showed that, between autumn 2005 and spring 2006, the number of new passengers who earlier used their cars for transport was tiny compared to the reduction in the number of passages over the charge cordon. Of the vehicle-traffic reduction of $22 \%$ over the charge cordon, at the most $0.1 \%$ can be ascribed to expanded bus traffic.

\section{The trial starts}

January 3 arrived, the system started, measurement data began rolling in, politicians and demonstrators stood at charging points and gave interviews in the freezing cold. I had been asked to be the chairman and spokesperson for the group of experts, comprising leading transport researchers, who were supposed to evaluate the effects of the trial continuously during the trial, and also summarise the extensive evaluation project once it was finished in the summer.

We thought it was extremely important to be in a position to say what had happened from the very first day. Even if the results from the first few days of the trial would not be significant for the long-term effects, we wanted to be able to demonstrate that we could track what was happening. Otherwise, it seemed to me, media would fill the information vacuum with the subjective experiences of journalists and more or less haphazard measurements of journey times. Anything could happen. The media image of how the trial was going and how the evaluation process was being handled would presumably be established at an early stage - during the first few days - and our obligation was to give the general public, who would eventually vote on the outcome of the trial, as objective and factually based a picture of the effects as possible. 
On the very first day one of the two things that surprised me most was apparent: that the effects could actually be seen. Practically all the experts were convinced that traffic would decrease, but few - and certainly not me - had expected that it could be seen with the naked eye. In normal circumstances, queue lengths and journey times vary considerably from day to day if the roads are congested. While the number of vehicles on larger roads typically only varies a few percent between similar days, queue lengths and journey times can vary enormously when congestion gets high. This fact, and considering that most commuters only see their little portion of the overall picture - a particular journey between a few places at a particular time on a particular day - meant that I (and probably nobody else) did not expect drivers to be able to notice the traffic reduction.

How wrong I was, was clear from the classic headline in Metro on the second day of the trial, based on the traffic figures we had provided them with - they were available and they were used! The headline "Every fourth car disappeared" was accompanied by two photographs side by side: the Klarastrand arterial the day before congestion charging came into operation, with a long, slow-moving queue of vehicles, and the same stretch of road the following day: an empty road with only a handful of cars clearly moving with no sign of any queues. I gaped in astonishment. We had all the figures - journey times, traffic flows - that said the same thing; but the pictures made the point so much more clearly.

And I was not the only one to be surprised. As the weeks passed and the effect remained constant, more and more people were surprised. I had almost expected that if the traffic measurements showed a traffic reduction (which I thought was likely), this would be questioned by the opposition, but if anything the opposite was the case. When we announced that the measurements showed that traffic levels inside the charging zone had dropped by about $25 \%$ - an enormous decrease - the reaction of most journalists was "yes, that's obvious" or even "really, is that all? The roads seem empty". It was not only in various places in the inner city that the effects could be seen. Bottlenecks near the cordon had been causing queues propagating out in the suburbs. With the charges in place, these queues almost vanished, with great congestion reduction in the suburbs as well.

\subsection{The wind turns}

Soon came the second surprise: public opinion began to change. After only a few weeks P.M. Nilsson, writing the editorial in the national evening tabloid Expressen, stuck his neck out and announced that he had changed his mind: this congestion charging business had turned out in fact to be a good idea. Many others followed P.M. Nilsson's lead. The media image changed more or less overnight - from "Congestion charging: even more chaos for road pricing"5 to "Stockholmers love congestion charging - People have realised the advantages - The dirge has turned into hymns of praise." Public opinion continued to change gradually until by the end of the spring there was a small majority in favour of the charges, according to the polls.

\footnotetext{
${ }^{5}$ Aftonbladet, December 22, 2005.

${ }^{6}$ Aftonbladet, January 14, 2006.
} 

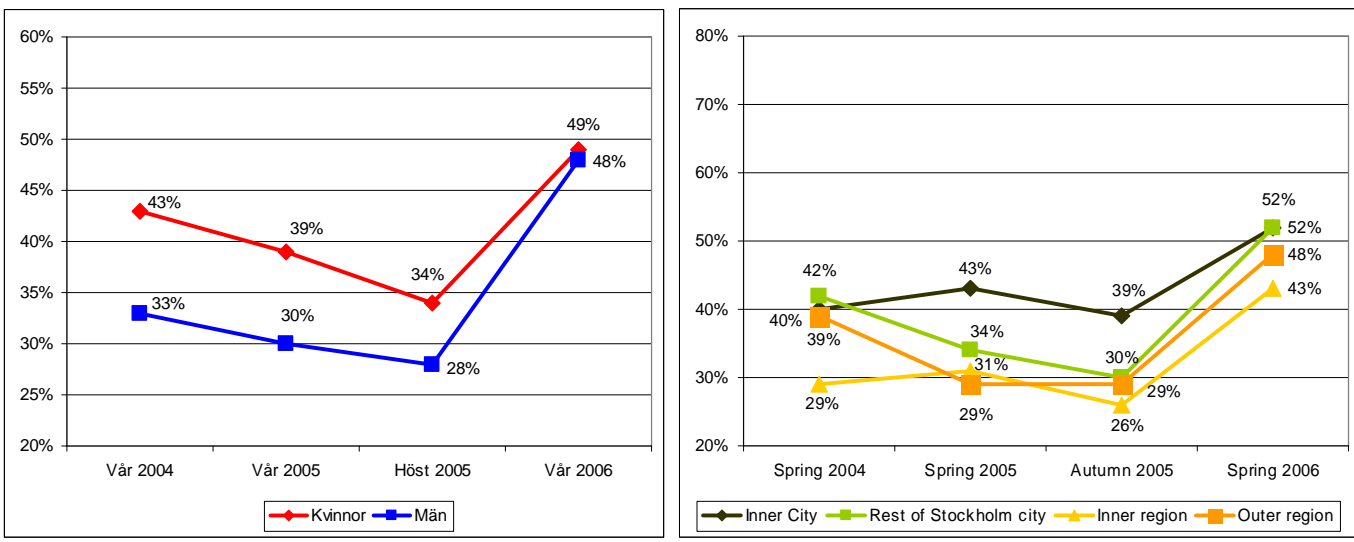

Figure 2. Share that would "very likely" or "rather likely" vote yes in a referendum on congestion charges. (By gender (left), from Byström and Vagland, 2007; by residential area (right), from Winslott-Hiselius et al, 2008).

There was no opportunity to pay at the control points. More than $60 \%$ of the payments were made automatically through transponder/direct debit. The rest were paid retroactively, either at local shops (7-eleven etc.) or through bank transfers, either direct transfer or using a "virtual shop" on the Internet where you could pay using e.g. a VISA card.

The technical system worked very well, both from a technical point of view and from an information point of view - people knew what to do, how to pay etc. Compliance with payments was very high, and the number of complaints was much lower than expected. On an average day in May 2006, 371,300 journeys took place over the charge cordon, resulting in 115,100 tax decisions and income of more than SEK 3 million. Of these 115,100 tax decisions, 100 were investigated by the Swedish Tax Agency and five were appealed. The Swedish Road Administration customer-service unit received on an average day in May 2,200 calls, as opposed to an expected 30,000 calls. Based on this, our assessment was that the system and the information generally worked well from a user's perspective.

However, studies of companies attitudes showed that many were having problems with the administration of the charges. The system for book-keeping and keeping track of vehicles were not well designed for the business needs, especially not initially. This was one of the main changes when the system was restarted in August 2007.

\subsection{The effects stabilised}

The goal was that the number of vehicles crossing the cordon should decrease 10$15 \%$. Our forecasts for the traffic effect made during the system design process actually pointed at a significantly larger decrease - around 20-25\% - but this was such a large decrease that it seemed unreasonable at the time. Further, it was unclear what effects on accessibility the charges would really have. While forecasts for traffic volumes are in general fairly credible, forecasts for travel times on heavily congested roads are in general not, since the only available forecasting tools were static network equilibrium models. Hence, it was decided that the system was probably appropriately designed. 
As it turned out, traffic flows across the cordon decreased almost exactly as predicted by the model. The decrease compared to the spring of 2005 remained at around $22 \%$ each month. As time passed it became increasingly clear that the effects were stable. After an initial period of two or three weeks when people were getting used to the charges and traffic levels reduced enormously, the reduction settled down at between 20 and $25 \%$ less traffic across the cordon during charged hours. Just like everybody else, we in the group of experts were curious to see if the effects would begin to fade away as people became used to the system, but the traffic decrease remained remarkably stable.

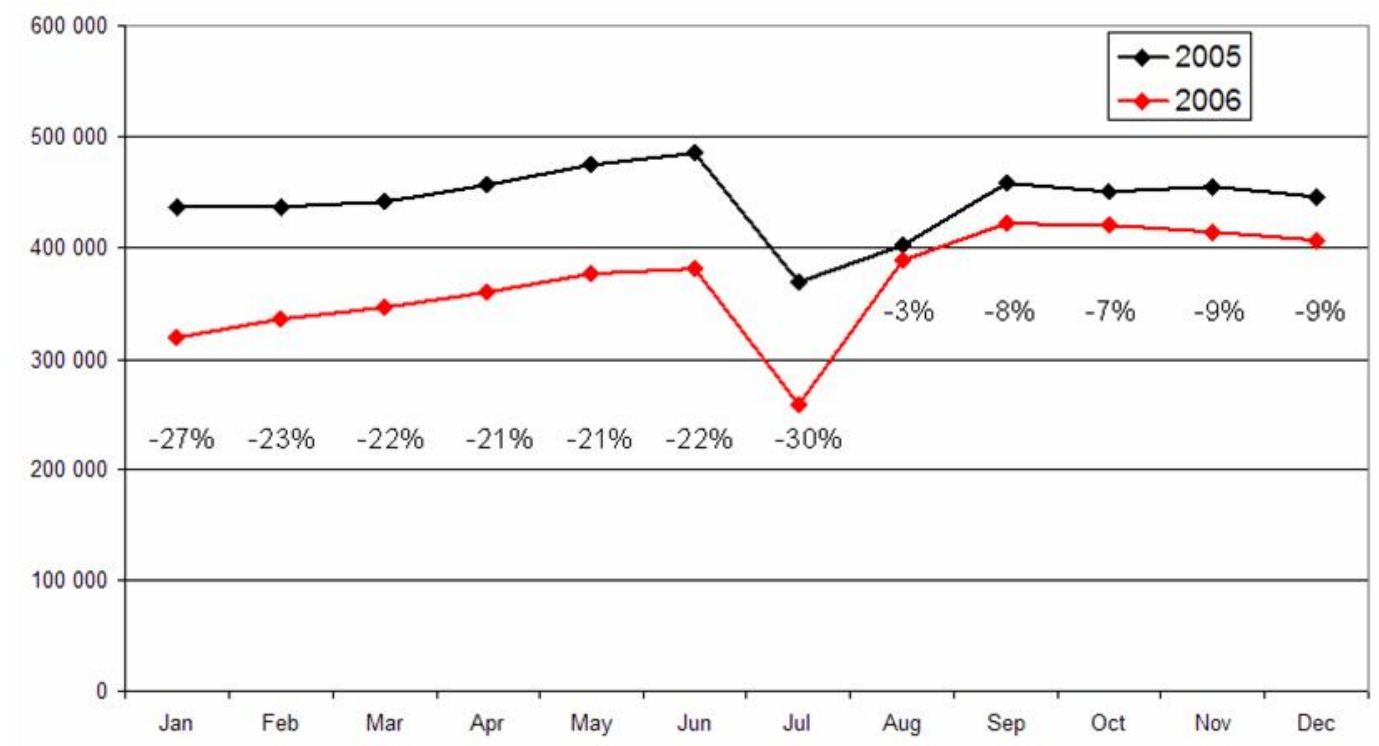

Figure 3. The number of vehicles passing across the cordon during daytime (6.00-19.00 weekdays). The charges were in place weekdays 6.30-18.30, January 3 - July 31, 2006. Data from Sept-Dec 2006 is uncertain due to road works and problems with the measurement equipment.

But to those people who did not study the percentage figures week by week, and merely looked around to see what the traffic was like, the picture seemed different. Traffic increases as spring proceeds and early summer approaches, and there are often sudden marked increases when the weather is warm and fine. Nobody knows for certain why, even part of the explanation is likely that people start driving out to their summer cottages, and that the number of trips per day increases when the weather is fine. Increased trip frequency tends to increase the share of car journeys, since going by car generally simplifies trip chaining. Moreover, traffic congestion increases because cars have to negotiate larger numbers of pedestrians and cyclists. The overall result is that traffic queues are always much longer in May and June than they are in the winter and early spring. This is a well-known phenomenon, but there was a risk that many would misinterpret the congestion increase as if the effects of the charges were "wearing off". We did whatever we could to minimise that risk. As early as March, the group of experts forecast that traffic density would increase as spring progressed into summer and would reach a peak shortly before Midsummer - not exactly a bold prediction! Sure enough, when the weather turned out to be warm around May Day, queues started to lengthen again. "It's just as bad as it was before congestion charging started," some people maintained - which shows how short people's memories are. In fact there was much less traffic than on a normal late spring day, and very much less than on a normal May day. 


\subsection{A summary of the effects}

The Stockholm trial was also special in that virtually no other traffic investment or regulation had ever been evaluated so thoroughly. Some 30 aspects were followed up - everything from vehicle movements to the perceived urban environment, even including aspects like garbage collecting, driving schools and children's participation in sports activities. Different parts of the evaluation were carried out by different consultants, research institutes and universities, and then it was the task of the expert panel to scrutinise and summarise all the evaluation reports.

Much of what happened had been expected. There was less traffic and hence fewer queues. The predictions had been correct in most important aspects. ${ }^{7}$ Throughout the charging zone traffic density decreased by an average of 20 to 25 per cent during the trial period - slightly less during the morning peak, slightly more during the afternoon/evening peak period.

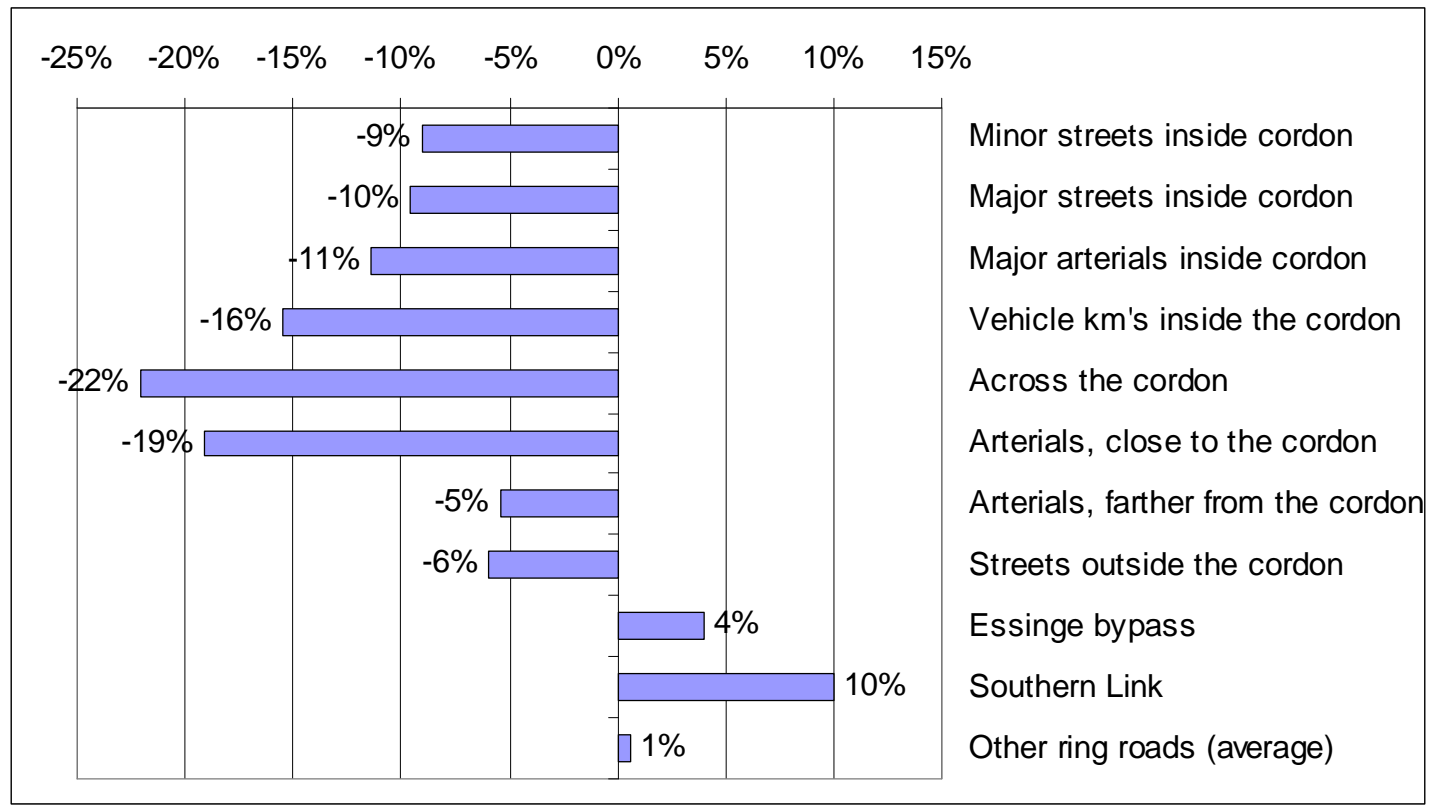

Figure 4. Reduction in traffic density during the charging period in per cent. (Data from City of Stockholm Traffic Office, 2006.) The increase on the Southern Link, which opened in late 2004, is mostly due to autonomous traffic growth.

Figure 3 shows the average reductions in traffic volumes on different kinds of roads and streets. The number of vehicle kilometres driven in the inner city, i.e. the number of kilometres driven, decreased by rather more than 15 per cent. The fact that this decrease was less is only to be expected because traffic in the inner city also includes journeys made by residents of the area and other drivers who do not leave the charging zone but use their vehicle to move around inside the inner city. Studies of driving habits suggested that drivers who had no need to cross the charging cordon took advantage of the decrease in congestion and used their vehicles more. This could be another part of the explanation as to why traffic density in the inner city decreased

\footnotetext{
${ }^{7}$ On the other hand the models do not work especially well in this context for calculating variations in traffic density at different times of day, a fact that has long been known. Another example of where a prediction was wrong was that the increase in traffic on Essingeleden became less than forecatsed.
} 
less than in the charging zone as a whole. Outside the inner city, on the outlying approach roads and outlying streets, traffic volumes fell by just over 5 per cent.

The problems on the Essinge bypass that several of us had feared turned out to be less than predicted. Average daily traffic volumes increased by a few percentage points, mainly outside the rush hours. Journey times on the Essinge bypass at peak times was more or less as bad as in the previous spring - some days worse, other days better. The shortage of road capacity between the northern and southern parts of Greater Stockholm is a strategic problem for the development of the area - but that was hardly a new discovery.

More dramatic than the reduction in the number of vehicles was the reduced time spent in queues, especially on the approach roads but also in the inner city. During the morning peak, the queue time, i.e. the extra travelling time caused by the queues, fell by about a third. During the afternoon/evening peak the reduction was even greater about fifty per cent.
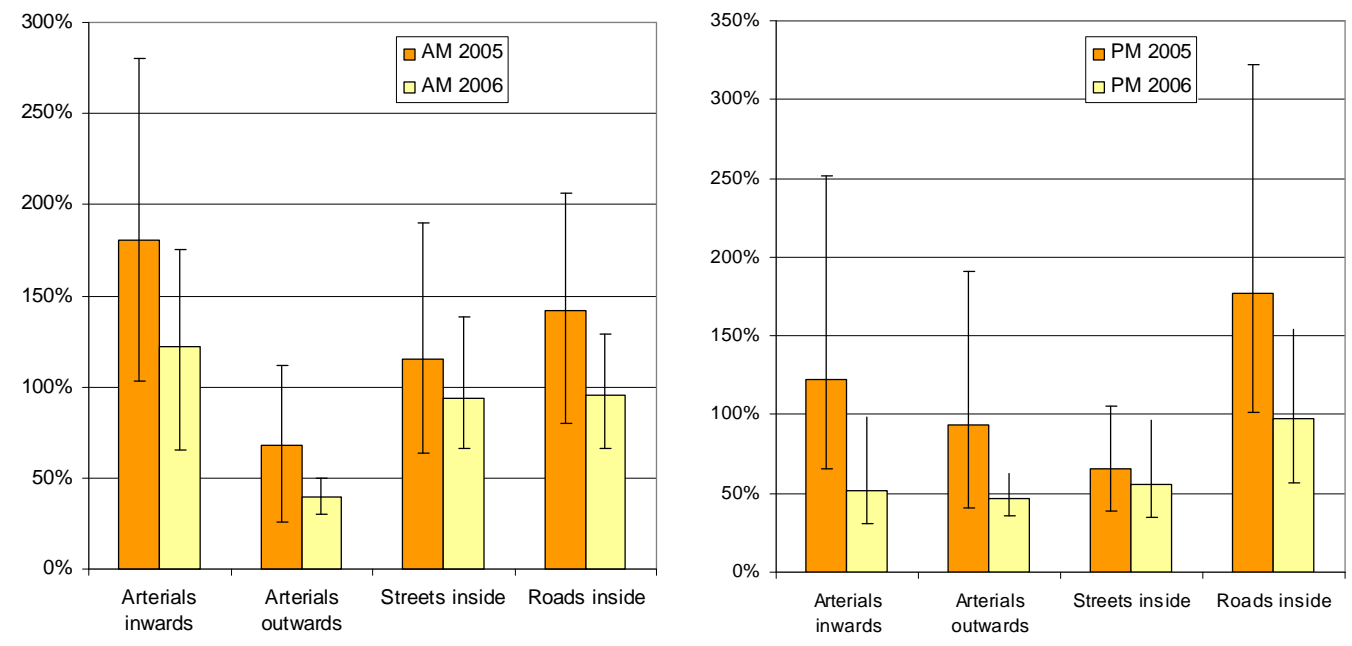

Figure 5. Relative increase of travel times for various categories of links. 0 percent corresponds to free-flow travel time. The coloured bars show average travel times while the "error bars" indicate the worst decile and the best decile of the travel-times distribution. Measurements were taken from all weekdays for six weeks in April-May. "AM peak" refers to 7.30-9.00, "PM peak" refers to 16.00-18.00.

The reduced congestion also meant that journey times became more predictable, i.e. the time spent in the car varied less from day to day. The black lines in the diagram above show the variations in journey times: the upper end shows the average 90percentile of the relative congestion, and the lower end shows the average 10percentile of the relative congestion. The $10 \%$ worst travel times was reduced even more than average travel times - for some categories of roads (such as arterials during PM peak), by a factor of 3 or more.

The reduction in vehicle kilometres travelled meant that dangerous exhaust emissions were also reduced. In the inner city, where exposure is at its height since it is so densely populated, the reduction was most marked, at between minus 10 and 15 per 
cent. ${ }^{8}$ Carbon dioxide emissions also fell, albeit only by a few per cent of the total emissions in the county of Stockholm.

There had been fears that retail inside the cordon would be adversely affected, but studies of the retail markets were not able to show any effects of the congestion charges. For example, the durables survey in shopping centres, malls and department stores during the Stockholm Trial period shows that these have developed at the same rate as the rest of the country. The same holds for other retail sectors.

\section{After the trial}

\subsection{The referendum and its interpretation}

The Stockholm trial was followed by referendums in the City of Stockholm and in about half of the neighbouring municipalities. The imitative to the referendums came initially from the opponents of the congestion charges, but once the idea was proposed, it was generally accepted by all political parties. This was more or less inevitable, since especially the Green party advocates more political referendums.

Since the opinion against the charges was so strong, suggesting a referendum seemed like a guaranteed way to block charges for a long time - at that time. Initially, only the City of Stockholm was planning a referendum. (The City of Stockholm is by far the largest municipality, accounting for almost half of the inhabitants of the County of Stockholm - the rest of the population is divided into 25 other municipalities.) In the autumn of 2005, opponents to the charges suggested that also surrounding municipalities should arrange referendums. The cordon lies entirely within the City's boundaries, and since municipalities have responsibility for "local transport and roads", the City argued that it was entirely up to the City to decide about the charges. Several surrounding municipalities - most vocally those governed by liberal/conservative majorities - argued that the issue affected their inhabitants as much as it affected the inhabitants of the City (which was not entirely true, judging from traffic and travel survey data). The City responded that since the City paid for the roads within its boundaries, why should it not be allowed to charge for the use of them? Moreover, the City argued, it was the inhabitants of the City that were most adversely affected by noise and emissions from traffic.

In the end, 14 of the surrounding municipalities arrange referendums of their own. All of the municipalities governed by liberal/conservative majorities arrange referendums, while most of the municipalities governed by social democratic/green majorities decide not to arrange referendums. The municipalities arranging referendums were also those with the greatest opinion against the charges.

The referendum in the City of Stockholm ended with a majority for keeping the charges (53\% in favour of the charges, $47 \%$ against them). The referendums in the neighbouring municipalities (accounting for around a quarter of the county inhabitants) ended with a majority against keeping the charges (40\% in favour of the charges, $60 \%$ against them). Around a quarter of the county inhabitants live in municipalities that did not have a referendum. Adding all votes up, a majority of the

\footnotetext{
${ }^{8}$ Different for different types of emission.
} 
voters were against the charges (48\% in favour of the charges, $52 \%$ against them) but then, the results could be viewed as a bit skewed, since most of the municipalities where polls showed a majority for the charges did not arrange a referendum at all, instead declaring that it was up to the City of Stockholm to decide about the charges.

The results of the referendum was thus difficult to interpret. The legal power over the charges lies with the national government (since it is a tax from a legal point of view, and municipalities are only allowed to tax its own inhabitants). It was at the outset unclear how the national government should interpret the result. The political debate over the charges had changed visibly during the trial. Before the trial, the opposition viewed the charges as a way to guarantee victory the City of Stockholm, and perhaps more than that, while the social democrats more or less tried to distance themselves from the charges - the referendum could be viewed as a way for voters to be against the charges while still voting for the social democrats. But during the trial, everything changed. The liberal/conservatives were not so keen on using the charge issue anymore (although this differed within the parties), while the social democrats were suddenly eager to use "success" (in their view, at least) of the charges during the election campaign.

The referenda coincided with general elections, which resulted in new majorities on the national, county and city level - liberal/conservative instead of the previous social democratic/green majorities. After pondering how to interpret the outcome of the referendums for a few weeks, the new national government decided that congestion charges should be reintroduced in August 2007, but that the revenues should be earmarked for road investments. The logic was that this should bolster the negative impact for the municipalities surrounding the City of Stockholm.

\subsection{Traffic effects after the trial}

When charges were abolished August 1, 2006, traffic immediately jumped back to its old level - almost. Surprisingly enough, there was a stable remaining traffic decrease of around 5-10\% compared to the 2005 level (and that level had been stable for around 15 years). Due to roadworks and problems with the measurement equipment, the size of the residual effect is a bit uncertain, but it was certainly there. One explanation could be that something else was affecting traffic levels - increased fuel prices for example. But this (and other things) had been checked meticulously with econometric methods, and increased fuel prices could at most explain $1 \%$ of the traffic decrease.

So why was there a residual traffic decrease? We don't know for certain, but I am inclined to believe that some car users developed new travel habits during the trial, which persisted even afterwards. My guess is that some car drivers found alternative modes or destinations that were actually better than they had thought before they tried them. Another, similar hypothesis is that there was a small but persisting "shift" in the travel habits in the sense that those commuters who used to go by car, say, three times out of five instead went by car, say, two times out of five. As mentioned above, many people are mixed-mode users: if some of these can decrease the share of car trips only somewhat, it will matter a lot - and will perhaps be persistent. This experience might suggest that information campaigns and similar measures have a greater potential for enticing car users to change their travel habits than at least I thought previously. 


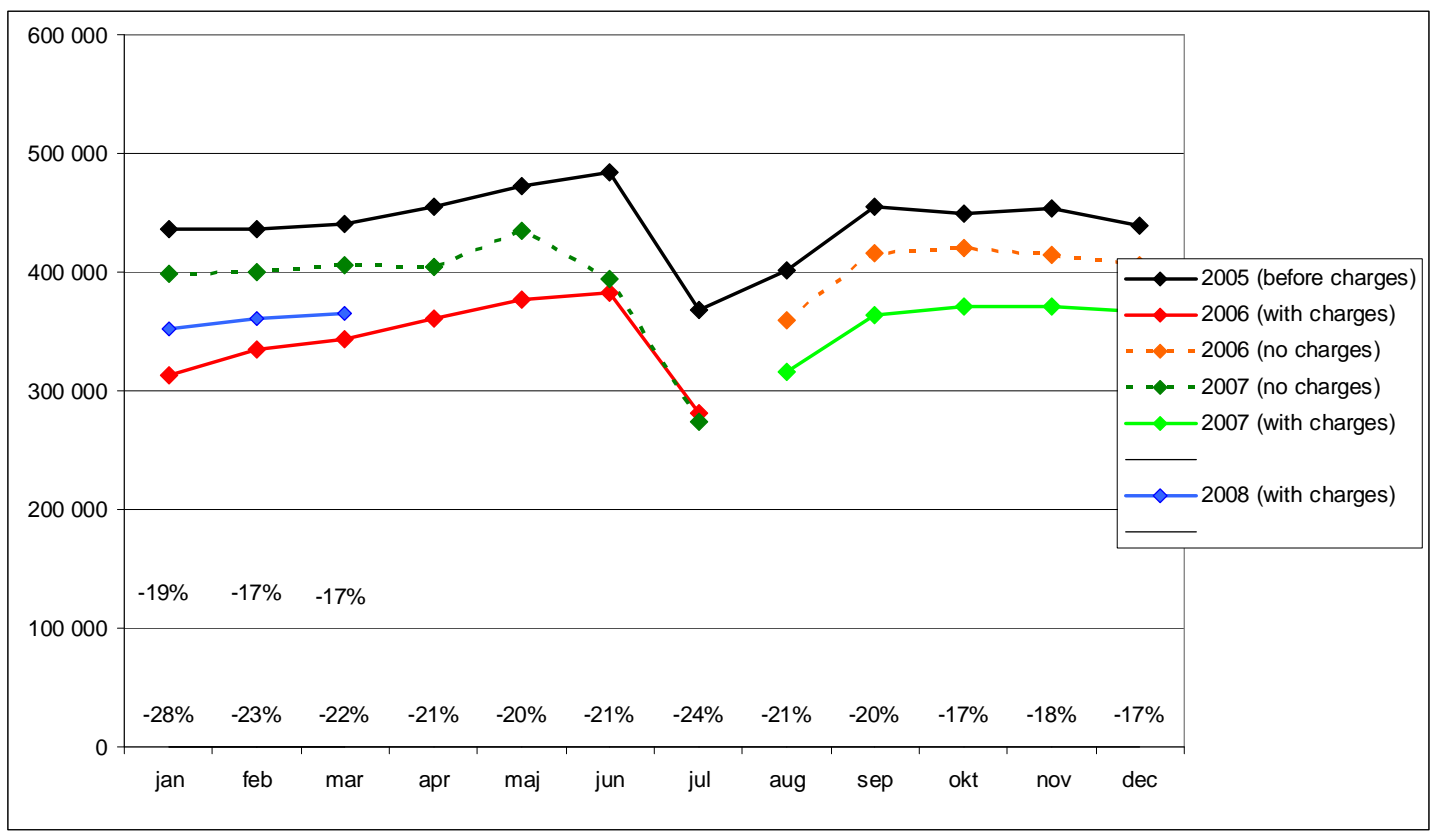

Figure 6. Traffic across the cordon, charged hours, 2005-2008. The period between when the charges were abolished and when they were reintroduced (dashed lines) are less certain, due to road works and technical problems with the measurement equipment.

When charges were reintroduced in August 2007, traffic was once again down 20\% compared to 2005 levels, i.e. around the same traffic levels as during the trial. Traffic has been slowly creeping up, but this does not seem to depend on car users "getting used to" the charges and returning to their old habits - it can be shown that the traffic increase in more than explained by increasing population and car ownership, and by inflation causing the charge to drop in real terms.

\section{Lessons from the Stockholm trial}

The fact that motorists were influenced by costs was hardly surprising, even if there were in fact those who maintained in advance that congestion charging would make no difference to traffic volumes. What were the surprises? I have already mentioned the two biggest ones: that journey times decreased by so much, over such a large area that it could be seen by the naked eye; and that public opinion changed from solid opposition to a slight majority in favour of congestion charging. ${ }^{9}-$

\subsection{Why did the opinion change?}

What was surprising about the change in opinion was that according to standard current transport-economic theory, most motorists would not think that the time saved was worth the charges they had to pay. Theoretically, the income from the charges is sufficient to compensate the losers, so the standard recommendation in the acceptance literature is that congestion charges must be part of a "package", within which it is clear how the income is going to be spent for the advantage of the general public, if it is going to have any chance of being accepted. (See for example Hau, 1995;

\footnotetext{
${ }^{9}$ At the moment of writing, there is a clear majority in favour of the charges. According to public opinion polls, 67 percent of the population of the City of Stockholm thinks it is good that congestion charging will be reintroduced. Stockholm City, 5 March 2007.
} 
Johansson \& Mattsson, 1990; Jones, 1991; Small, 1992; Thomson, 1998; Langmyhr, 1997.)

In the case of the Stockholm trial, however, virtually none of the income would be used for the direct benefit of motorists. It is true that some of the income was used to improve public transport during the course of the trial, but not very many would be able to take advantage of that. So the majority of the citizens of Stockholm ought to have thought that, on the whole, they were losers.

But that is not how things turned out. To my astonishment (and I think the same applied to most of my colleagues) more and more people came to support the congestion charges. Of course, they had to pay: but in return, they were able to get to where they wanted to go much more quickly. And many, albeit by no means all, seemed to think that the time saving was worth the charges they had to pay - contrary to the standard theory.

I think the standard theory missed three things. First: network effects. Since queues propagate "upstream", even those not going through the actual bottleneck will suffer from queues. Pricing traffic in the bottleneck to reduce queues, all upstream traffic will benefit. In the Stockholm case, many people found their journeys easier to make without having to pay anything at all, because traffic flow improved both inside and outside the inner city - not only on the charged roads. Second: the effect on the urban environment. Typically, standard analysis of congestion charges takes no account of effects for pedestrians or cyclists - or might be called "the perceived urban environment effect". It is possible that reduced exhaust emissions played a part in this "urban environment effect", although it was hardly of such magnitude that it could be appreciated without measuring equipment.

Third: the self-selection effect on trips and on the value of time. Simplifying somewhat, standard theory assumes that all motorists have a joint value of time. But congestion charges will tend to "sort" trips such that trips with high value will stay on the road (and enjoy time benefits), while low-valued will be priced off. Not taking this phenomenon into account will underestimate the value of the time benefits. from an acceptance perspective, the important point is that individuals can belong to different "groups" on different days, or different journeys. A lot of the car journeys that "disappeared" were the kind that the motorists concerned did not even notice that they had cancelled. The fact is that when motorists were asked if the congestion charging had made them change their travelling habits, there were too few answering "yes" to correspond with the actual reduction in traffic density according to the measurements made. ${ }^{10}$ About half the "vanished" car journeys were shopping trips, leisure activities and other journeys that could be changed to different times or places, or suspended for some other reason. ${ }_{-}^{11}$

It is striking how many that actually admitted that they had changed their minds. A well-known phenomenon is the tendency to self-rationalise, and not admit even to oneself that one has changed one's mind. But in this case, a large percentage of people - roughly 35 per cent - responded to the direct question "Have you changed

\footnotetext{
${ }^{10}$ The City of Stockholm Traffic Office (2006), p. 48.

${ }^{11}$ The other half of the "vanished" journeys were journeys to work or school that used public transport instead of a motor car.
} 
your mind during the trial?" by answering "Yes, I've become more positive towards it." 12 It is in this connection that I consider P.M. Nilsson to be a model. How often nowadays does one hear intellectuals, editorials or politicians admitting that they were wrong and have changed their minds? Interestingly, in December 2007, after the reintroduction of the charges in August 2007, a new survey on the congestion charges asked whether people had changed their mind about the charges during the trial. This time, only $22 \%$ said that they had changed their mind. Apparently, roughly a third of those who changed their mind during the trial had now forgotten that they had done so.

\subsection{The fast and multi-faceted adaptation of travel patterns}

Another surprise was that the effects appeared and stabilised so fast. Even more surprising was perhaps that it was so difficult to discover where the vehicles had "disappeared" to. I suspect that we in the expert panel, like most people, were unconsciously stuck with the assumption that there is a more or less fixed number of trips to be made, and that the effect of the charges would be possible to sort neatly into categories like "mode change", "destination change" and "departure time change". For work and school trips, this was more or less true: most of the "disappearing" work/school trips ended up in public transport. But for discretionary trips, making up around half of the "disappearing" trips, the adaptations were much more multi-faceted, to the point that it was hard to say what had really happened. One of the observations was that people's travel patterns seem to vary more from day to day than is generally acknowledged. My impression is that experts, researchers and laymen share a more or less unconscious view of travel patterns as "stable". But the lesson from the travel surveys, the attitude surveys and the traffic measurements is that travel patterns are much more flexible and different from day to day than most of us generally think.

\subsection{A simple design that worked}

An interesting observation was that the comparatively simple charging system worked reasonably well. It is true that the way in which the toll varied according to the time of day was fairly detailed, but the system was simplistic compared to a truly optimal system. Nevertheless, a number of refinements would be desirable. I think the most important one is to vary the congestion charges according to the time of year, with low charges or even none at all during high summer, and higher charges between May Day and Midsummer than for the rest of the year.

\subsection{Congestion charging is a potent and cost-efficient measure}

One important conclusion, admittedly nothing new, was that congestion charging is very effective in reducing traffic congestion when compared with other, much more expensive measures such as road and rail developments, or reduced fares on public transport. New roads and rail tracks are needed for many reasons - there is insufficient capacity with regard to both road and rail in the regional centre - but to invest in them would not be a long-term way to reduce significantly congestion in and around the inner city. For example, the planned Eastern and Western bypass are forecasted to reduce traffic in and around the Stockholm city centre by between 10 and 15 per cent - that is about half the effect of congestion charging - and cost about 15 and 25 billion kronor respectively to build (National Road Administration, 2006a,

\footnotetext{
${ }^{12}$ The City of Stockholm Office of Research and statistics (2006).
} 
2006b). Zero fares on public transport has been calculated to reduce the number of vehicle kilometres driven by only two or three per cent, and would cost about 5 billion kronor per year. Strictly speaking, comparisons of this sort are unfair, as the motives for the bypasses are not primarily to reduce road congestion, but to improve accessibility between the various parts of the region. Nevertheless, it does illustrate how difficult it is to invest in transport developments designed to reduce congestion in the inner city and on the approach roads. As investments in road and rail projects are charged to the public purse, while congestion charging yields an income of 500-600 million kronor per year (after reductions for running costs), it is unreasonable to compare such investments with congestion charging, as if they were substitutes for each other. As far as costs and the effect on traffic movements are concerned, it makes more sense to think of them as being complementary.

A more depressing conclusion was that the substantial extensions of the public transport did not succeed in wooing over many motorists. This does not mean that there was no point in trying. It was necessary to do so in to take care of evicted car users - overcrowding on public transport was not much worse than it had been before congestion charging was introduced - and the passengers who used the new direct buses were very satisfied. Public transport that works satisfactorily is naturally a must if a big city is going to function properly, and develop. But if it were to be regarded as the only way of reducing the volume of traffic to and from the inner city, this measure was - as expected - more or less useless.

\subsection{Why a "success"?}

I never thought I would read anything like what appeared in Dagens Nyheter when the general assessment of the Stockholm Trial was published at the end of June: "At last the experts have come to the conclusion that the citizens of Stockholm know already. Congestion charging has been a success." Every part of that sentence was a surprise: primarily, of course, that the trial could be designated a "success". But it was also surprising that the experts had actually managed to "come to a conclusion", given all the difficulties faced during the assessment process - and that Dagens Nyheter could write that "the citizens of Stockholm know already" - in other words, that the effects of congestion charging were so obvious to the naked eye that even without access to the technical measurements, the man in the street could see that there was far less traffic on the roads.

So why was the congestion charges viewed as a success? My impression was that there were four important reasons for this.

- The technical system worked. That the system worked from the start was of course a key factor. The number of misidentifications was extremely low, and from users' perspectives, everything worked seamlessly. Further, the Road Administration made great efforts to develop a customer-friendly system.

- The information campaign had worked. Apparently, people knew what to do. Anticipated problems with people who didn't know that they should pay, or didn't know how to pay, didn't materialise. Moreover, the anticipated problem of protests in the form of large number of court appeals or refusals to pay was 
never a problem. in spite of a lot of talk before the trial about "civil disobedience" in the form of refusal to pay or appealing to court.

- Visible congestion reduction. The improvements of travel times and the urban environment were visible right from the start. The astonishment of seeing almost empty streets during rush hours, in particular during the first months, cannot be stressed enough. After that, the potency of road pricing had been overwhelmingly proved, and the negative arguments shifted from "it won't work" to other, often more constructive, arguments.

- Extensive and scientific evaluation. Even if effects were visible, one should stress the importance of being able to supply media with hard figures about the reduction of traffic volumes and congestion. Especially when the debate recovered somewhat from the initial shock caused by the enormous initial effects, it was extremely important to have professional, independent researchers and experts, coming from different backgrounds and organisations, being able to explain and evaluate what was happening. The size of the evaluation was itself an important factor: so many experts and researchers were involved in one way or another that it was impossible to wave it away.

- Clear objectives. The system had clear and measurable objectives - reducing congestion and improving the environment in the inner city - and the system was visibly designed with these objectives in mind. Moreover, the objectives were fulfilled.

Apart from these "success factors", we also know that environmental concerns was a big factor. Recent polls have shown that there is a strong correlation between the attitude in environmental issues and the attitude to congestion charges - the more concerned about environmental issues someone is, the more positive to the congestion charges.

\subsection{Good or bad?}

So, is congestion charging all upsides? No, certainly not. Even if the aggregate effect is beneficial for a city's transport system, many individuals will have to make sacrifices. This is especially true in the short and medium term, when some people are forced to change their travelling habits and everyday activities as a result of the congestion charges. These sacrifices have to be weighed against the positive effects of the charges on the environment and accessibility, and the possibility to use the revenues for necessary investments - which has to be paid for somehow: as usual, there is no such thing as a free lunch. In my opinion, it makes more sense to raise the necessary money in a way that also happens to improve accessibility and environment, than to get the money through for example increased income taxes with all its well-known distortionary effects.

Having to pay for something that used to be free is never popular, and some people will be worse off - especially in the short term, until new travelling habits become gradually adopt. And we do not know very much about what is going to happen in the longer term. It is likely that traffic volumes will continue increasing just as it has done to date, decade after decade. But the anticipated overall increase in traffic makes me even more convinced that congestion charging, all things considered, is a useful and probably even necessary way of ensuring that a big city's transport systems continue to work reasonably efficiently. That is not a controversial opinion among transport 
researchers. What is unique about the Stockholm trial is that this view appears to have taken root outside such this relatively small circle as well.

\section{References}

Ahlstrand, I. (1998) The rise and fall of the heroic transport plan for Stockholm. Transport Policy 5, p. 205-211.

Byström, C. and Vagland, ̊. (2007) Attitudes to the Stockholm trial. Working paper presented at the conference "What do we learn from the Stockholm Congestion Charging Trial?", Centre for Transport Studies, KTH, May 2007.

Dupuit, J. (1849) On tolls and transport charges. Reprinted in Intl. Econ. Papers 1962 (11), 731.

Eliasson, J. and Ljungberg, M. (2002) Road pricing in urban areas, National Road Administration Publication 2002:136E, available at www.vv.se.

Hau, T. (1995) A conceptual framework for pricing congestion and road damage. In Johansson, Börje and Mattsson, Lars-Göran (eds.): Road pricing: Theory, empirical assessment and policy, Dordrecht.

HMSO [Ministry of Transport] (1964) Road Pricing: The Economic and Technical Possibilities. Her Majesty's Stationery Office, London, 1-61.

Johansson, B. and Mattsson, L-G. (1995) "Principles of road pricing" in Johansson, Börje and Mattsson, Lars-Göran (eds.): Road pricing: Theory, empirical assessment and policy, Dordrecht.

Jones, P. (1995) "Road pricing: the public viewpoint", in Johansson, Börje and Mattsson, Lars-Göran (eds.): Road pricing: Theory, empirical assessment and policy, Dordrecht.

Jones, P. (1991) Gaining public support for road pricing through a package approach. Traffic Engineering and Control, April 1991.

Winslott-Hiselius, L., Brundell-Freij, K., Vagland, Å, and Byström, C. (2008) The development of public attitudes towards the Stockholm congestion trial. Forthcoming in Transportation Research A.

Knight, F.H. (1924) Some fallacies in the interpretation of social costs. Quarterly Journal of Economics 38, 582-606.

Langmyhr, T.(1997) Managing equity - the case of road pricing. Transport Policy 4, 25-39.

Malmsten, B. and Persson, M. (2001) Dennispaketet - låsningar och lösningar (The Dennis package - deadlocks and unlockings) Regionplane- och trafikkontoret vid Stockholms läns landsting (Regional Planning and Traffic Office at the Greater Stockholm Council).

May, A. (1992) Road pricing: An international perspective. Transportation 19, No. 4.

National Road Administration (2006a) Förstudie Östlig förbindelse (Preliminary study, the eastern link), Borlänge.

National Road Administration (2006b) Samhällsekonomiska kalkyler för Nord-sydliga förbindelser i Stockholm (Cost-benefit analysis north-south links in Stockholm), Borlänge.

Pigou, A.C. (1918) The economics of welfare, London.

Small, K. (1992) Using the revenues from congestion pricing. Transportation 19, 359-381. 
The City of Stockholm Environmental Charging Secretariat (2006) Facts and results from the Stockholm Trial, second version August 2006. Available at www.stockholmsforsoket.se.

The City of Stockholm Office of Research and statistics (2006) Knowledge of and attitudes towards the Stockholm Trial. Available at www.stockholmsforsoket.se.

The City of Stockholm Traffic Office (2006) Evaluation of the effects of the Stockholm trial on motor vehicle traffic. Available at www.stockholmsforsoket.se.

Thomson, M. (1998) Reflections on the economics of traffic congestion. Journal of Transport Economics and Policy 32, 93-112. 